\title{
Redução da exigência de fósforo disponível em dietas com adição de fitase para frangos de corte machos de oito aos 21 dias de idade
}

John Armando Parra-Martín*, D.Sc. ${ }_{1}$, Luiz Fernando Teixeira Albino, D.Sc. ${ }_{1}$, Horacio Santiago Rostagno, Ph.D. ${ }_{1}$, Melissa Izabel Hannas, D.Sc. ${ }_{1}$, Elcer Zamora-Jeréz, D.Sc. (c) 1

Resumo. Introdução: na formulação de rações para frangos de corte (FC), usam-se fontes inorgânicas de fósforo $(\mathrm{P})$. O P fítico (que provém dos vegetais das rações) e os excessos de $\mathrm{P}$ inorgânico adicionados são eliminados nas fezes e causam problemas ao ambiente. Objetivou-se avaliar a redução da exigência de fósforo disponível (Pd) FC machos submetidos a três níveis de Pd com fitase (500FTu kg-1 de ração) no período dos oito aos 21 dias de idade sobre desempenho e parâmetros ósseos. Material e método: usaram-se $480 \mathrm{FC} \mathrm{Cobb}$, distribuídos em delineamento inteiramente casualizado. Os níveis de Pd foram 0,391\% (nível da exigência de FC machos de desempenho médio) e mais dois níveis: $-10 \%$ e $+10 \%$. A relação do cálcio com o $\mathrm{Pd}$ foi de 2,13:1 (Ca:Pd). Tiveram-se oito repetições e 20 aves por boxe e foi ministrada uma dieta isonutriente. Avaliaram-se peso final, ganho de peso, consumo de ração, conversão alimentar e, nas tíbias, os teores de cinzas, $\mathrm{P}$ e Ca. Os dados obtidos foram submetidos à ANOvA; quando houve diferença significativa $(\mathrm{P}<0,05)$, as médias dos tratamentos foram comparadas pelo teste de SNK. Resultados: o consumo de ração diminuiu $(\mathrm{P}=0,0265)$ no nível $110 \%$. Quanto à mineralização óssea, o nível de $90 \%$ resultou em menor teor de cinzas ( \%), de cálcio ( \% e g) e de $\mathrm{P}(\%$ e g) $(\mathrm{P}<0,05)$. Conclusão: é possível diminuir a exigência de Pd em FC machos quando for avaliado seu desempenho. É possível que dietas que contenham $10 \%$ a menos da exigência de $\mathrm{Pd}$ para FC machos atendam às necessidades de mineralização óssea do animal.

Palavras-chave: cálcio, desempenho, enzima, fitato, fosfato bicálcico, mineralizão óssea. 


\title{
Reducción de la exigencia de fósforo disponible en dietas con adición de fitasa para pollos de engorde machos de 8 a 21 días de edad
}

Resumen. Introducción: en la formulación de concentrados para pollos de engorde (FE), se usan fuentes inorgánicas de fósforo (P). El P fítico (que proviene de los vegetales de los concentrados) y los excesos de P inorgánico agregados se eliminan en las heces y causan problemas al ambiente. Su objetivo fue evaluar la reducción de la exigencia de fósforo disponible (Pd) en FE machos sometidos a tres niveles de Pd con fitasa (500FTu kg-1 de concentrado) entre los 8 y 21 días de edad sobre el desempeño y los parámetros óseos. Material $y$ método: se usaron $480 \mathrm{FC} \mathrm{Cobb}^{\circ}$, distribuidos en delineamiento enteramente casualizado. Los niveles de Pd fueron 0,391 \% (nivel da exigencia de FE machos de desempeño mediano) y más dos niveles: $-10 \%$ e $+10 \%$. La relación del calcio con el Pd fue de 2,13:1 (Ca:Pd). Se hicieron ocho repeticiones y 20 aves por box y se suministró una dieta isonutriente. Se evaluaron peso final, aumento de peso, consumo de concentrado, conversión alimentar $\mathrm{y}$, en las tibias, los contenidos de cenizas, $\mathrm{P}$ y $\mathrm{Ca}$. Los datos recolectados se sometieron a ANOvA; cuando hubo diferencia significativa $(\mathrm{P}<0,05)$, los promedios de los tratamientos fueron contrastados por el Test de SNK. Resultados: el consumo de concentrado disminuyó $(\mathrm{P}=0,0265)$ en el nivel del $110 \%$. En cuanto a la mineralización ósea, el nivel del $90 \%$ resultó en menor contenido de ceniza ( \%), de calcio ( \% e g) y de $\mathrm{P}(\%$ e g; $\mathrm{P}<0,05)$. Conclusión: es posible disminuir la exigencia de Pd en FE machos cuando sea evaluado su desempeño. Asimismo, dietas que contengan el 10\% menos de la exigencia de Pd para FE machos atienden a las necesidades de mineralización ósea del animal.

Palabras clave: calcio, desempeño, enzima, fitato, fosfato bicálcico, mineralización ósea.

\section{Reducing the demand for available phosphorus in diets with added phytase for 8-to-21-day-old male broilers}

\begin{abstract}
Introduction: in formulating concentrates for broilers (FE), inorganic sources of phosphorus (P) are used. Phytic P (derived from vegetables in concentrates) and excess added inorganic $\mathrm{P}$ are eliminated in the stool and cause problems to the environment. The aim of this study was to evaluate the reduction of the demand for available phosphorus (Pd) in 8-to-21-day-old male FE subject to three levels of Pd with phytase $\left(500 \mathrm{FTU} \mathrm{kg}^{-1}\right.$ of concentrate) on performance and bone parameters. Materials and methods: $480 \mathrm{Cobb}^{\oplus} \mathrm{FE}$ were used and distributed according to a completely randomized design. Pd levels were $0.391 \%$ (level of demand for male FE with medium performance) plus two levels: $-10 \%$ and $+10 \%$. The ratio between calcium and Pd was 2.13:1 (Ca:Pd). 8 replications of 20 birds per box were performed and an iso-nutrient diet was provided. Final weight, weight gain, concentrate intake, feed conversion, and ash, $\mathrm{P}$ and $\mathrm{Ca}$ contents in tibias were evaluated. Collected data were submitted to ANOva; where there was a significant difference $(\mathrm{P}<0.05)$, the treatment averages were compared by the sNK test. Results: concentrate intake decreased $(\mathrm{P}=0.0265)$ at the level of $110 \%$. As for bone mineralization, the $90 \%$ level resulted in lower ash (\%), calcium ( \% e g) and $\mathrm{P}(\%$ e g; $\mathrm{P}<0.05)$ contents. Conclusion: it is possible to decrease the demand for Pd in male FE when their performance has been evaluated. Also, diets containing $10 \%$ less than the demand for Pd in male FE meet the needs for animal bone mineralization.
\end{abstract}

Keywords: calcium, performance, enzyme, phytate, dicalcium phosphate, bone mineralization. 


\section{Introdução}

No mundo, um terço das carnes consumidas por humanos é de frango [2]. Em 2012, foram produzidas mais de 90 milhões de toneladas desta carne [3].

$\mathrm{Na}$ formulação de rações para frangos de corte (FC), é usado o fósforo (P) que é adicionado na ração animal, geralmente na forma de fosfato bicálcico $(\mathrm{Fb})$. No animal, o P é fundamental na manutenção, no desenvolvimento e no reparo de tecidos; junto com o cálcio $(\mathrm{Ca})$, participa na mineralização óssea onde se pode encontrar aproximadamente até $80 \%$ do $\mathrm{P}$ no organismo. O restante fica em compostos orgânicos com função metabólica (ATP, DNA, RNA, fosfolipídios das membranas celulares, entre outros), transporte de gorduras e síntese de aminoácidos e proteínas [4]. O Fb fornece $\mathrm{P}$ na forma inorgânica $(\mathrm{Pi})$, que é de alta disponibilidade para o animal, mas, ao se encontrar com o ácido fítico, complexo que provém dos ingredientes vegetais das rações, diminuiu àquela disponibilidade [5].

Tanto o fósforo fítico quanto o excesso de Pi adicionado são eliminados nas fezes e causam sérios problemas ao ambiente [6], que provocam diminuição da quantidade de oxigênio $\left(\mathrm{O}_{2}\right)$ nas águas dos rios e lagos (eutrofização) e o acúmulo de metais pesados no solo [7], além da lixiviação destes para o lençol freático e da contaminação do solo [8]. Além dessa problemática, as reservas do mineral estão se esgotando [9], o que encarece os custos de produção e obriga o uso de fontes alternativas do mineral. As fitases (c.45.1.4: myo-inositol hexafosfato fosfohidrolase [10]) hidrolisam o fósforo fítico e promovem maior aproveitamento do $\mathrm{P}$ da ração, o que leva à diminuição na quantidade de inclusão de fosfato bicálcico na dieta.

O presente estudo teve como objetivo avaliar a redução da exigência de Pd de frangos de corte alimentados com três níveis de fósforo disponível com adição de fitase (500 $\mathrm{FTU} \mathrm{kg}^{-1}$ de ração) no período dos oito aos 21 dias de idade no desempenho e em parâmetros ósseos.

\section{Material e método}

O presente estudo esteve de acordo com os princípios éticos da experimentação animal, estabelecidos pelo Colégio Brasileiro de Experimentação
Animal e com a legislação vigente, e foi aprovado pelo Comitê de Ética para Uso de Animais do Departamento de Zootecnia da Universidade Federal de Viçosa (Protocolo 021-2012).

O ensaio foi conduzido no Setor de Avicultura do Departamento de Zootecnia (Centro de Ciências Agrarias) da Universidade Federal de Viçosa (Minas Gerais, Brasil), no período compreendido entre maio e julho de 2012, na cidade de Viçosa, na Zona da Mata de Minas Gerais, a 2045'S de latitude e $42^{\circ} 51^{\prime}$ wg de longitude, altitude média de 692,73m, clima CWA [11], com temperatura média anual de $294,05^{\circ} \mathrm{K}$ e precipitação pluviométrica $1203 \mathrm{~mm}^{3}$ por ano. O período experimental foi de 14 dias: do dia oito ao dia 21. Foram utilizados 480 pintos de corte Cobb ${ }^{\circ}$ [12] machos de oito dias de idade e com peso médio de $180 \mathrm{~g}$, distribuídos em um delineamento inteiramente casualizado. A ração experimental (tabela 1) foi isoenergética e isoproteica, à base de milho e farelo de soja, e formulada para atender às necessidades nutricionais de frangos de corte machos de desempenho médio conforme níveis recomendados, sempre mantendo a relação Ca:Pd em 2,13:1 e assumindo a disponibilidade de $\mathrm{P}$ dos ingredientes vegetais a partir de valores existentes; o nível de referência de Pd foi assumido como $100 \%$ e foram formuladas mais duas dietas com níveis: $-10 \%$ e $+10 \%$, isto é, $90 \%$, $100 \%$ e $110 \%$ [1]. Os níveis foram suplementados com fosfato bicálcico e adição de fitase (500FTU $\mathrm{kg}^{-1}$ de ração), e considerou-se o aporte da matriz da enzima (tabela 2). A enzima utilizada foi uma 6-fitase de origem bacteriana (Escherichia coli) expressa na levedura Pichi pastoris [13, 14]. As aves receberam ração e água à vontade.

As aves foram alojadas em 24 boxes $\left(2,25 \mathrm{~m}^{2}\right.$ cada) com piso de cimento e maravalha em galpão de alvenaria, com dimensões $4,5 \mathrm{~m}$ x 19,4m x 2,8m de pé direito, situado no sentido Leste-Oeste, com lanternim, laterais com muretas de $0,5 \mathrm{~m}$ de altura e o restante fechado com tela de $1 / 2$ " e cortinas com abertura de cima para baixo.

Durante todo o período experimental, adotou-se o programa de luz de 24 horas de luz (natural mais artificial) e utilizaram-se lâmpadas de 60W e lâmpadas infravermelho de $250 \mathrm{~W}$ para aquecimento. A temperatura diária foi mensurada (às $08 \mathrm{~h}$ e às $16 \mathrm{~h}$ ) no interior dos galpões com termômetros de máxima e mínima. 
Tabela 1. Ração experimental para a fase inicial (oito a 21 dias)

\begin{tabular}{|c|c|c|c|}
\hline Ingredientes & $90 \%$ & $100 \%$ & $110 \%$ \\
\hline Milho 7,88\% & 59,892 & 59,892 & 59,892 \\
\hline Farelo de soja $45 \%$ & 35,094 & 35,094 & 35,094 \\
\hline Óleo de soja & 1,325 & 1,325 & 1,325 \\
\hline Areia & 0,800 & 0,505 & 0,210 \\
\hline Calcário calcítico & 0,956 & 1,040 & 1,123 \\
\hline Fosfato bicálcico & 0,588 & 0,799 & 1,011 \\
\hline Sal comum & 0,405 & 0,405 & 0,405 \\
\hline DL-Metionina $99 \%$ & 0,247 & 0,247 & 0,247 \\
\hline L-Lisina/HCl 78,4\% & 0,182 & 0,182 & 0,182 \\
\hline L-Treonina 98,5\% & 0,021 & 0,021 & 0,021 \\
\hline Suplemento mineral ${ }^{1}$ & 0,110 & 0,110 & 0,110 \\
\hline Suplemento vitamínico² & 0,110 & 0,110 & 0,110 \\
\hline Cloreto de colina $60 \%$ & 0,100 & 0,100 & 0,100 \\
\hline Salinomicina $12 \%$ & 0,055 & 0,055 & 0,055 \\
\hline Avilamicina $10 \%^{4}$ & 0,010 & 0,010 & 0,010 \\
\hline внт & 0,010 & 0,010 & 0,010 \\
\hline Amido & 0,080 & 0,080 & 0,080 \\
\hline Fitase & 0,010 & 0,010 & 0,010 \\
\hline Total & 100 & 100 & 100 \\
\hline \multicolumn{4}{|c|}{ Níveis calculados e analisados de cálcio e fósforo total } \\
\hline Energia metabolizável, Mcal/kg & 3,000 & 3,000 & 3,000 \\
\hline Proteína bruta, $\%$ & 21,275 & 21,275 & 21,275 \\
\hline Cálcio, \% & 0,750 & 0,833 & 0,916 \\
\hline Cálcio analisado, \% & 0,603 & 0,683 & 0,764 \\
\hline Fósforo total calculado, \% & 0,455 & 0,494 & 0,533 \\
\hline Fósforo total analisado, \% & 0,474 & 0,512 & 0,551 \\
\hline Fósforo disponível, \% & 0,352 & 0,391 & 0,430 \\
\hline Lisina digestível, \% & 1,174 & 1,174 & 1,174 \\
\hline Lisina total, \% & 1,276 & 1,276 & 1,276 \\
\hline Metionina + Cistina digestível, \% & 0,846 & 0,846 & 0,846 \\
\hline Metionina + Cistina total, $\%$ & 0,925 & 0,925 & 0,925 \\
\hline Arginina digestível, \% & 1,361 & 1,361 & 1,361 \\
\hline Treonina digestível, \% & 0,763 & 0,763 & 0,763 \\
\hline Treonina total, \% & 0,867 & 0,867 & 0,867 \\
\hline Triptofano digestível, \% & 0,251 & 0,251 & 0,251 \\
\hline Triptofano total, $\%$ & 0,274 & 0,274 & 0,274 \\
\hline Valina digestível, \% & 0,904 & 0,904 & 0,904 \\
\hline Valina total, \% & 1,012 & 1,012 & 1,012 \\
\hline
\end{tabular}

${ }^{1}$ Suplemento mineral aves - Composição por kg de ração: cobre, 1,1g; ferro, 5,5g; iodo 0,11g.; manganês, 7,7g; selênio, 33mg; zinco, 7,15g.; veículo.

${ }^{2}$ Suplemento vitamínico - Composição por kg de ração: vit. A, 825000UI; vit. D3, 209000UI; vit. E 3080UI; vit. B1, 0,22g; vit B2, 0,55mg; vit. B6, 0,308g; B12, 1,32mg; vit. K3, 0.165g; ác. Pantotênico, 1,1g; ácido nicotínico 3,3g; ácido fólico, 77mg; biotina, 7,7mg; antioxidante não reportado; veículo.

Fonte: elaboração própria 
Tabela 2. Nutrientes contidos na matriz da fitase usada*

\begin{tabular}{|l|c|}
\hline \multicolumn{1}{|c|}{ Nutrientes da matriz } & Contribuição na dieta \\
\hline Fósforo disponível \% & 0,130 \\
\hline Cálcio \% & 0,143 \\
\hline Energia metabolizável, $\mathrm{kcal} \mathrm{kg}^{-1}$ & 45,000 \\
\hline Proteína bruta \% & 0,365 \\
\hline Lisina digestível \% & 0,015 \\
\hline Treonina digestível \% & 0,029 \\
\hline Triptofano digestível \% & 0,017 \\
\hline AAs- Cisteina digestível $\%$ & 0,033 \\
\hline Valina digestível \% & 0,015 \\
\hline
\end{tabular}

* Dados fornecidos pelo fabricante $[13,14]$.

Fonte: elaboração própria

A mortalidade foi registrada para correção dos dados de desempenho. As aves e as rações foram pesadas no início (aos oito dias) e aos 21 dias de idade para determinação de ganho de peso, do consumo de ração e para o cálculo da conversão alimentar. Aos 21 dias de idade, cinco aves na média de peso de cada repetição ( $\pm 10 \%)$, o que totaliza 40 aves por tratamento, foram abatidas pelo procedimento de eletronarcose e sangria.

As tíbias foram totalmente descarnadas e separadas da cartilagem e da fíbula. Foi feita pré-secagem em estufa de secagem com circulação por convecção natural $\left(338,15^{\circ} \mathrm{K}\right.$ por 72 horas). Em seguida, os ossos foram desengordurados com éter, triturados em moinho de bola e homogeneizados. A secagem definitiva foi feita em estufa de secagem com convecção forçada $\left(378,15^{\circ} \mathrm{K}\right.$ por 16 horas). A quantificação das cinzas ósseas consistiu da incineração das tíbias por quatro horas a $873,15^{\circ} \mathrm{K}$ para determinação do percentual do resíduo expresso na matéria seca desengordurada. A solução mineral para a determinação de fósforo e cálcio foi obtida das cinzas por via seca; a determinação do fósforo foi realizada pelo método de fotometria; o cálcio foi determinado por absorção atômica com chama; as análises foram feitas de acordo com a metodologia proposta $[15,16]$. As cinzas o cálcio e fósforo foram expressos como proporção e quantidade total ( \% e g).

Foi utilizado delineamento inteiramente casualizado com três níveis de Pd, oito repetições e 20 aves por unidade experimental. Os dados obtidos foram submetidos à análise de variância; quando houve diferença significativa $(\mathrm{P}<0,05)$, as médias dos tratamentos foram comparadas pelo teste de Student-NewmanKeuls. As análises estatísticas dos parâmetros analisados foram realizadas utilizando-se o programa SAEG [17] e ASsistat [18].

O modelo de análise de variância foi: $Y i j l=$ $\mu+D j+E i j l$, em que:

Yijl = observação do período $\mathrm{I}$, da dieta $\mathrm{j}$ e a repetição l;

$\mu=$ efeito médio geral;

$D j$ = efeito da dieta $\mathrm{j}$, sendo $\mathrm{j}=$ níveis de fósforo disponível;

$E i j l=$ efeito do erro aleatório atribuído à observação na dieta j, na repetição 1 , no período I.

\section{Resultados e discussão}

Os resultados de peso final, de ganho de peso, de consumo de ração e de conversão alimentar obtidos com

Tabela 3. Médias de desempenho para frangos de corte machos de oito a 21 dias de idade, de acordo com diferentes níveis de fósforo disponível*

\begin{tabular}{|l|c|c|c|c|c|c|}
\hline \multicolumn{1}{|c|}{ Tratamento } & $\begin{array}{c}\text { Níveis } \\
\text { Ca:Pd }\end{array}$ & $\begin{array}{c}\text { Peso inicial } \\
(\mathbf{k g})\end{array}$ & Peso final $(\mathbf{k g})$ & $\begin{array}{c}\text { Ganho de peso } \\
(\mathbf{k g})\end{array}$ & $\begin{array}{c}\text { Consumo } \\
\text { ração }(\mathrm{kg})\end{array}$ & $\begin{array}{c}\text { Conversão } \\
\text { alimentar }\end{array}$ \\
\hline $\mathbf{9 0} \%$ & $0,750: 0,352$ & 0,180 & 0,796 & 0,615 & $0,951^{\mathrm{a}}$ & 1,546 \\
\hline $\mathbf{1 0 0} \%$ & $0,833: 0,391$ & 0,180 & 0,785 & 0,605 & $0,955^{\mathrm{a}}$ & 1,578 \\
\hline $\mathbf{1 1 0} \%$ & $0,916: 0,430$ & 0,181 & 0,778 & 0,597 & $0,917^{\mathrm{b}}$ & 1,539 \\
\hline Média & - & - & 0,786 & 0,606 & 0,941 & 1,554 \\
\hline $\mathbf{C V}(\boldsymbol{\%})$ & - & - & 3,730 & 4,740 & 2,960 & 2,630 \\
\hline
\end{tabular}

* Nível de $5 \%$ de probabilidade.

Nota: médias seguidas por letras distintas na mesma coluna diferem entre si pelo teste SNK a $5 \%$ de probabilidade.

Fonte: elaboração própria 
frangos de corte machos $\mathrm{Cobb}^{\circ}$ no período dos oito aos 21 dias de idade estão apresentados na tabela 3 .

Não houve diferenças significativas $(P>0,05)$ entre níveis de Pd para as variáveis peso final, ganho de peso nem conversão alimentar. Para a variável consumo de ração, houve diferenças $(\mathrm{P}=0,0265)$ entre o nível $110 \%$ e os demais.

Nesse período, observou-se que o uso de níveis de Pd de $90 \%$ resultou em valores semelhantes ao dos níveis $100 \%$ quando analisada a variável consumo de ração; os níveis $110 \%$, por sua vez, reportaram decréscimo nos resultados; isso pode ser explicado porque provavelmente haja uma maior quantidade de $\mathrm{Ca}$ e de $\mathrm{P}$ no lúmen intestinal, o que pode estar diminuindo a taxa de passagem dos nutrientes [19] por formação de fitina, sal de ácido fítico com o $\mathrm{Ca}^{2+}$ [20], composto insolúvel em $\mathrm{pH}$ neutro [21]. Quanto ao desempenho, para o nível $90 \%$, estão sendo verificados valores iguais aos reportados pelos do nível $100 \%$. Esses dados concordam com achados prévios de desempenho zootécnico [22], os quais usaram aves que consumiram ração com Pd reduzido $(0,35 \%)$ e adição de fitase, e os resultados foram semelhantes aos obtidos com alimentação controle (Pd 0,45\%).

Para a variável ganho de peso, os dados foram iguais, o que pode ser explicado pela digestibilidade ileal da proteína bruta, do cálcio e do fósforo, que, quando usada fitase, aumenta a quantidade de nutrientes [23], o que justificaria também o peso final das aves.

As médias de teor de cinzas, de cálcio e de fósforo na tíbia de frangos de corte machos de oito a 21 dias de idade, de acordo com diferentes níveis de Pd e de cálcio na ração estão apresentadas na tabela 4 .

Não houve diferenças $(\mathrm{P}>0,05)$ entre os níveis de Pd para a variável peso da tíbia nem quantidade de cinzas, foi numericamente maior no nível $100 \%$ quando comparado com os níveis $90 \%$ e $110 \%$. Para as demais variáveis, verificou-se que, à medida que os níveis de Pd aumentavam os resultados, tinham um comportamento linear; portanto, houve diferenças significativas para as variáveis percentual de cinzas $(\mathrm{P}=<0,001)$, percentual de $\mathrm{Ca}$ $(\mathrm{P}=0,0012)$, quantidade de $\mathrm{Ca}(\mathrm{P}=0,0078)$, percentual de $\mathrm{P}(\mathrm{P}<0,001)$ e quantidade de $\mathrm{P}(\mathrm{P}=0,00042)$; os menores valores foram encontrados no nível $90 \%$ quando comparado com os outros dois níveis.

Um estudo [19] revelou que houve uma redução na concentração de Ca e de $\mathrm{P}$ nas tíbias das aves alimentadas com dieta que continha baixo nível de P $(0,24 \%)$ em relação aos valores obtidos com a dieta controle $(0,354 \%$ de $\mathrm{P})$ na fase de crescimento. Ao diminuir o conteúdo de $\mathrm{P}$ da dieta, reduz-se significativamente o conteúdo de cinzas no osso da tíbia [24]. Essas mudanças são aparentemente o resultado de um mecanismo de feedback homeostático que causa um incremento na formação de 1,25-dihidroxicolecalciferol (calcitriol) nas células tubulares do rim. O calcitriol aumenta a absorção de $\mathrm{Ca}$ e $\mathrm{P}$ do intestino delgado, eleva os níveis séricos de $\mathrm{Ca}$ [25] e, assim, supre a secreção do hormônio paratireoide (РTH) [26]. A partir dos resultados obtidos, verifica-se que o nível de $90 \%$ (0,352 \%) foi o suficiente para garantir o mesmo desempenho do que o nível $100 \%$, porém não foi suficiente para

Tabela 4. Médias dos parâmetros ósseos para frangos de corte machos de oito a 21 dias de idade, de acordo com diferentes níveis de fósforo disponível*

\begin{tabular}{|l|c|c|c|c|c|c|c|c|}
\hline \multirow{2}{*}{ Tratamento } & \multirow{2}{*}{$\begin{array}{c}\text { Níveis } \\
\text { Ca:Pd }\end{array}$} & $\begin{array}{c}\text { Peso } \\
\text { tíbia }\end{array}$ & \multicolumn{2}{|c|}{ Cinzas } & \multicolumn{2}{c|}{ Cálcio } & \multicolumn{3}{c|}{ Fósforo } \\
\cline { 3 - 10 } & $(\mathbf{g})$ & $(\%)$ & $(\mathrm{g})$ & $(\%)$ & $(\mathrm{g})$ & $(\%)$ & $(\mathrm{g})$ \\
\hline $\mathbf{9 0} \%$ & $0,750: 0,352$ & 1,905 & $45,705^{\mathrm{c}}$ & 0,871 & $13,591^{\mathrm{b}}$ & $0,257^{\mathrm{b}}$ & $9,002^{\mathrm{b}}$ & $0,171^{\mathrm{b}}$ \\
\hline $\mathbf{1 0 0} \%$ & $0,833: 0,391$ & 1,942 & $46,949^{\mathrm{b}}$ & 0,913 & $17,170^{\mathrm{a}}$ & $0,335^{\mathrm{a}}$ & $10,813^{\mathrm{a}}$ & $0,210^{\mathrm{a}}$ \\
\hline $\mathbf{1 1 0} \%$ & $0,916: 0,430$ & 1,899 & $47,678^{\mathrm{a}}$ & 0,906 & $16,698^{\mathrm{a}}$ & $0,317^{\mathrm{a}}$ & $11,485^{\mathrm{a}}$ & $0,218^{\mathrm{a}}$ \\
\hline Média & - & 1,916 & 46,778 & 0,897 & 15,820 & 0,303 & 10,433 & 0,200 \\
\hline $\mathbf{C V}(\%)$ & - & 9,410 & 1,410 & 10,060 & 11,330 & 15,250 & 6,880 & 10,080 \\
\hline
\end{tabular}

* Nível de $5 \%$ de probabilidade.

Nota: médias seguidas por letras distintas na mesma coluna diferem entre si pelo teste SNK a $5 \%$ de probabilidade.

Fonte: elaboração própria 
maximizar a deposição óssea, uma vez que o nível $100 \%$ apresentou maiores resultados.

Já tinha sido verificado [27] que os parâmetros ósseos são mais sensíveis para avaliar as fontes e níveis de $\mathrm{P}$ para aves, e que a exigência mínima para ótimo desempenho é inferior à requerida para máxima mineralização do tecido ósseo; assim, esses níveis de Pd abaixo da exigência podem reduzir a deposição de matéria mineral no referido tecido, o que pode influenciar negativamente a integridade $\mathrm{e}$ a resistência óssea [28].

\section{Conclusões}

É possível diminuir a exigência de Pd em FC machos de desempenho médio quando avaliados parâmetros zootécnicos.

É possível que dietas que contenham $10 \%$ a menos da exigência de Pd para FC machos atendam às necessidades de mineralização óssea do animal. Neste estudo, não foi verificada resistência óssea.

Recomenda-se o uso da exigência de Pd de $100 \%(0,391 \%)$ quando adicionada fitase ao nível de $500 \mathrm{FTu} \mathrm{kg}^{-1}$ de ração como estratégia para diminuir a quantidade de Pi adicionado às dietas.

\section{Agradecimentos}

Agradecemos à ABvista por fornecer a enzima. $\mathrm{O}$ primeiro autor agradece à Coordenação de Aperfeiçoamento de Pessoal de Nível Superior (Capes) a bolsa para estudos de doutorado.

\section{Referências}

[1] Rostagno HS, Albino LFT, Donzele JL, Gomes PC, Oliveira RF, Lopes DC, Ferreira AS, Barreto SLT, Euclides RF. Tabelas brasileiras para aves e suínos. Composição de Alimentos e Exigências Nutricionais. $3^{\mathrm{a}}$ ed. Universidade Federal de Viçosa, Departamento de Zootecnia; 2011.

[2] Bradesco. Carne avícola. Depec - Departamento de Pesquisas e Estudos Econômicos; 2015 [acesso em 9 ago. 2015]. Disponível em: http://www.economiaemdia.com.br/EconomiaEmDia/pdf/infset_ carne_avicola.pdf

[3] Faostat [internet]. Roma (IT): Food and Agriculture Organization of the United Nations Statistics Divi- sion (Iт) [2015] - Meat chicken world production [acesso em 9 ago. 2015]. Disponível em: <http:// faostat.fao.org/site/569/DesktopDefault.aspx?PageID $=569$ \#ancor $>$

[4] France J, Dias RS, Kebreab E, Vitti DMSS, Crompton LA, Lopes S. Kinetic models for the study of phosphorus metabolism in ruminants and monogastrics. Em: Phosphorus and calcium utilization and requirements in farm animals. Vitti DMSS, Kebreab E, editores. Piracicaba, CABI; 2010. p. 18-44.

[5] Tizziani T. Níveis de fósforo disponível em rações suplementadas com fitase para frangos de corte dos 22 aos 42 dias mantidos em ambiente de alta temperatura [Dissertação Magister Scientiae]. Universidade Federal de Viçosa; 2014.

[6] Sartaj M, Fernandes L, Patni NK. Performance of forced, passive, and natural aeration methods for composting manure slurries. As. J. Food Ag-Ind. 2009 mar.-abril; 40(2):457-63.

[7] Kelley TR, Pancorbo OC, Merka WC, Thompson SA, Cabrera ML, Burhart HM. Accumulation of element in fractionated broiler litter during reutilization. J Appl Poultry Res, Athens 1998; 7(1):27-34.

[8] Conte AJ. Valor nutritivo do farelo de arroz integral em rações para frangos de corte, suplementadas com fitase e xilanase [Doutorado em Zootecnia]. Universidade Federal de Lavras; 2000.

[9] Us Geological Survey. [internet]. (us): U.S. Department of the Interior | us Geological Survey (us) [2015] — Phosphate rock. us Geological Survey, Mineral Commodity Summaries, janeiro 2015. Disponível em: http://minerals.usgs.gov/minerals/ pubs/mcs/2015/mcs2015.pdf

[10] IUPAC - International Union Of Biochemistry. Enzyme nomenclature: Recommendations of the Nomenclature Committee of the International Union of Biochemistry. Nova York: Academic Press; 1979.

[11] Köppen W, Geiger R. Klimate der Erde. Gotha: Verlag Justus Perthes. Wall-map 150cmx200cm; 1928

[12] Cobb-Vantress Inc. Manual de manejo de frangos de corte Cobb. Cobb-Vantress Inc.; Brasil. 2009.

[14] Formulating with Quantum 5000 - Poultry. 3 Woodstock Court, Blenheim Road, Marlborough Business Park, Marlborough, Wiltshire, SN8 4AN [acesso em 12 out. 2012]. Reino Unido. Disponível em: http://www.abvista.com/assets/download/130.

[15] Silva DJ, Queiroz AC. Análise de Alimentos: métodos químicos e biológicos. $3^{\mathrm{a}}$ ed. Viçosa: UFV; 2002.

[16] Detmann E, Souza MA, Filho SCV, Queiroz AC, Berchielli TT, Saliba EOS, Cabral LS, Pina DS, Ladeira MM, Azevedo JAG. Métodos para análise de alimentos. Visconde de Rio Branco: INCT-Ciência animal; 2012. 
[17] UFV — Universidade Federal de Viçosa. SAEG — Sistema de análises estatísticas e genéticas. Versão 8.0. UFv, Viçosa, Brasil [Manual do usuário]; 2007.

[18] UfCG - Universidade Federal de Campina Grande. The Assistat-Statistical Assistance Software. AssisTAT, UFCG, Campina Grande, Brasil; 2009.

[19] Lan GQ, Abudullah N, Jalaludin S, Ho YW. Efficacy of supplementation of a phytase-producing bacterial culture on the performance and nutrient use of broiler chickens fed corn-soybean meal diets. Poultry Sci 2002;81(10):1522-32.

[20] McKnight WF. The impact of phytase and high available phosphorus corn on broiler performance and phosphorus excretion. Em: Proceedings of the Basf Technical Symposium, 1999, Atlanta, GA. BASF Corp., Mount Olive, NJ. Anais Atlanta: BASF; 1999 (Seção 6). p. 57-66.

[21] Rebollar PG, Mateos GG. El fósforo en nutrición animal. Necesidades, valoración de materias primas y mejora de la disponibilidad. xv Curso de Especialización Avances en nutrición y alimentación animal; 1999.

[22] Parmer TG, Carew LB, Alster FA, Scanes CG. Thyroid function, growth hormone, and organ growth in broilers deficient in phosphorus. Poult Sci. 1987;66(12):1995-2004.

[23] Tejedor AA, Albino LFT, Rostagno HS, Vieites FM. Efeito da adição da enzima fitase sobre o desempenho e a digestibilidade ileal de nutrientes. RevBras Zootecn 2001;30(3):802-8.

[24] DeLuca HF. Parathyroid hormone as a trophic hormone for 1,25-dihydroxyvitamin D3, the metabolically active form of vitamin D. N. Engl. J. Med. 1972;287(5):250-1.

[25] Tanaka Y, Deluca HF. The control of 25-hydroxyvitamin D metabolism by inorganic phosphorus. Arch Biochem Biophys. 1973;154(2):566-74.

[26] Schoulten NA, Teixeira AS, Bertechini AG, Freitas RTF, Conte AJ, Silva HO. Efeito dos níveis de cálcio sobre a absorção de minerais em dietas iniciais para frangos de corte suplementadas com fitase. Ciênc Agrotec 2002; 26(6):1313-21.

[27] Gomes PC, Runho RC, D’Agostini P, Rostagno HS, Albino LFT, Lopes PS. Exigência de Fósforo Disponível para Frangos de Corte Machos e Fêmeas de 22 a 42 e de 43 a 53 Dias de Idade. R Bras Zootecn. 2004;33(6):1734-46 (Supl. 1).

[28] Unep. Industry and environment. Cleaner Production Seventh International High-level Seminar Prague 7. jul.-dez.; 2002 [acesso em 13 abril 2015]. Industry and environment. Disponível em: http:// www.uneptie.org/division/media/review/vol25no3-4/I\&E25_34.pdf 